\title{
Causes and consequences of donor perceptions of the quality of the relationship marketing activities of charitable organisations
}

Received: 18th October, 2004

\section{Roger Bennett}

is a professor and the Director of the Centre for Research in Marketing at London Metropolitan University. His career has included ten years in management consultancy plus periods in the mining and metallurgical industries and with a leading commercial bank. Roger is the author of a large number of books and numerous journal articles on various aspects of marketing and business management.

\section{Anna Barkensjo}

is a research assistant in the Centre for Research in Marketing at London Metropolitan University. Her main research interests lie in the field of nonprofit and voluntary sector marketing, especially the ways in which charitable organisations employ marketing techniques when dealing with their beneficiaries.

Roger Bennett

Department of Business and Service Management, London Metropolitan University, 84 Moorgate, London EC2M 6SQ, UK.

Tel: +44020 7320 1577; Fax: +44020 7320 1465; e-mail:

r.bennett@londonmet.ac.uk

\begin{abstract}
Although relationship marketing has been adopted extensively and enthusiastically by UK charitable fundraising organisations, the operational assessment of what actually constitutes 'good quality' relationship marketing by charities has been overlooked. This paper presents the results of an investigation into the perceptions of the quality of charities' relationship marketing activities reported by a sample of 141 known regular supporters of charities. Three forms of relationship marketing were considered: relationship advertising, direct marketing, and 'two-way marketing contacts' (public relations events, open days, and other two-way marketing communications). The calibre of each of these genres of relationship marketing was evaluated in terms of five criteria: message relevance, interactive engagement, and the arousal of feelings of commitment, benevolence and trust. A donor's overall perception of the quality of an organisation's relationship marketing was conceptualised as a latent variable formed (rather than reflected) by the individual's opinions of the attributes of the three above mentioned methods of relationship marketing. Connections between the latent relationship marketing quality variable and (i) the levels and frequencies of supporters' donations, and (ii) donors' future intentions to continue giving to the charity, were then examined. The model was estimated using the technique of partial least squares.
\end{abstract}

\section{INTRODUCTION}

The research reported in the present paper explored the possible existence of linkages between donors' perceptions that a charity's relationship marketing activities were of 'high quality', and their levels of financial contribution to and intentions regarding the continuation of their support for the charity. British charitable organisations are heavily 
involved in relationship marketing, ${ }^{1-4}$ due, inter alia, to a growing awareness that, as in the commercial world, it is considerably cheaper to retain and satisfy existing donors (customers) than it is to acquire new recruits. McGrath ${ }^{5}$ noted that the typical UK charity experiences an annual wastage rate of between 10 per cent and 20 per cent of all supporters who make more than one contribution (such donors representing about 50 per cent of the total). Thus, around half of all the people who give to a charity more than once are likely to disappear every three to five years. As the costs of obtaining replacements are substantial, investments in effective relationship marketing are typically worthwhile. ${ }^{6}$ Normally, the upfront cost of procuring a supporter exceeds the financial value of the person's contributions during the first year of a relationship. Indeed, several years might be needed to recoup initial recruitment expenses. $^{7}$

Around 11 per cent of all UK direct mail is attributable to charities, ${ }^{8}$ much of it intended to build relationships with donors. (The charitable sector's contribution to the volume of UK postings is marginally below that of mail order companies (13 per cent), but well above the figures for other major mailers, eg insurance companies (7 per cent) and banks (4 per cent)). Increasingly, charities engage in face-to-face high street marketing intended to induce donors to commit themselves to ongoing monthly or quarterly direct debit donations. Indeed, in 2003 a BBC Radio 4 investigation of the activities of commercial fundraisers operating on behalf of British charities noted a growing public concern about the practice of approaching people in the street and asking them to set up standing orders. The BBC claimed that less than 10 per cent of the amounts pledged went to a good cause in the first year of the arrangement. ${ }^{9}$

Nonetheless, charities continue to undertake face-to-face fundraising because it enables them to initiate and consequently to nurture long-term relationships with fresh supporters, resulting in high lifetime donor values. (The British Red Cross increased its face-to-face recruitment by 20 per cent in 2003. ${ }^{10}$ ) Similar considerations apply to the practice of approaching employees of businesses and asking them to participate in payroll giving. ${ }^{11}$

Otherwise, charities engage in a plethora of relationship marketing activities, including telemarketing, ${ }^{12}$ database marketing, ${ }^{13}$ the sale of charity-branded products and memorabilia, and 'bonding' events such as open days or gala dinners. ${ }^{14}$ Public relations events create norms and expectations concerning a charity's operations and, critically, can develop a donor's sense of shared values and affiliation with an organisation. ${ }^{15}$ The development of database marketing, ie 'direct marketing based on highly specific databases which can focus on profiles of income, lifestyles, location, geography and many niche segments ${ }^{16}$ has greatly stimulated relational approaches to fundraising. Database marketing enables a charity to collect and analyse large amounts of information about its supporters, to segment its donor markets in detail, and hence to direct personalised communications to actual or potential supporters. Differentiated messages can be conveyed to donors according to their known characteristics and preferences.

For decades, charities have sold (usually via mail order catalogues and brochures) low-value items such as Christmas cards, coffee mugs, T-shirts, trinkets and other memorabilia that carry a charity's name and logo with the aim of invoking in donors deeper levels of 
organisational attachment. A notable trend in the marketing activities of a number of well-known UK charities during recent years has been their diversification into the supply of branded products not directly connected with the main philanthropic aims of the organisations concerned. Conspicuous examples of the phenomenon include the Personal Equity Plans (PEPs), insurance, savings and current accounts and other financial services offered by Friends of the Earth; the sale of burglar alarms by Age Concern; and the flowers-by-post gift service launched in 1996 by Age Concern in partnership with three other charities. Many charities offer branded credit cards. Barnardos, for example, operates a retail loyalty card in conjunction with a major chain of retailers; the Royal British Legion provides branded discount telephone cards to its supporters. ${ }^{17} \mathrm{~A}$ major objective of associating a charity brand with a product is the encouragement of donor loyalty. ${ }^{18}$ The materials accompanying the sale can also be used to communicate the charity's mission and core values. ${ }^{19}$ Bennett ${ }^{20}$ found that the duration of a donor's association with a charity was longer the wider the range of categories of the person's involvement with the organisation (eg purchasing charity branded products, using a charity-affiliated credit card, selling raffle tickets on behalf of a charity, participating in charity sponsored events). These interactions created trust in and liking for a charity.

Further relationship-building activities completed by fundraising charities include invitations to donors to become involved in supporters' clubs, volunteer activities and the sale of raffle tickets. Additionally, individuals who give might be sent thank-you letters accompanied by a newsletter or video showing aspects of the charity's activities. ${ }^{21}$ Online donors can be rewarded via a downloadable screensaver or computer game that is made available once the person has hit the 'donate' button on the charity's website and pledged a certain minimum sum of money.

Indubitably, a large amount of charity marketing is aimed at donor retention and the cultivation of one-to-one relationships with supporters. Relationship marketing is important for charitable organisations, and many UK charities have invested heavily in relationship marketing techniques. It is somewhat surprising, therefore, that little attention has to date been paid to the assessment of the impact of relationship marketing on donor behaviour and, in particular, on donors' intentions vis-à-vis the continuation of relationships. The study described below sought to help fill this lacuna in contemporary knowledge of charity fundraising through a survey of the reactions to relationship marketing of a sample of 141 known regular supporters of UK charities, and the connections between various forms of response and (i) levels of donation, and (ii) intentions to continue supporting the organisation. Although the research was undertaken in the nonprofit relationship marketing context, the outcomes should be of considerable interest to managers of the relationship marketing function in any form of organisation, as they offer valuable insights into the overall effectiveness of relationship marketing. The paper proceeds as follows. First the nature, advantages and possible problems of charity relationship marketing are briefly discussed. Then the techniques of relationship marketing commonly employed by charities are described and their desired outcomes delineated. Next the methodology of the study is presented and a number of propositions and measures are developed. Details of how the propositions were tested on 141 
charity supporters are given and the reliability and validity of the results are evaluated. The paper concludes with an assessment of the practical implications of the findings for charity fundraising management.

\section{RELATIONSHIP MARKETING BY CHARITABLE ORGANISATIONS}

Relationship marketing seeks to establish, develop and maintain relationships with clients (donors in the present context). This differs from 'transactional' marketing that focuses on attracting and satisfying new clients, as opposed to building relationships. Berry ${ }^{22}$ and Guenzi ${ }^{23}$ argued that relationship marketing was particularly relevant for situations where people 'identified' with an organisation and where its services were seen as important and involving. These criteria are normally satisfied in relationships between donors and charities. ${ }^{24,25}$ Also, it is increasingly possible (through database marketing) to personalise a charity's contacts with its supporters, and interactivity with donors is commonplace (eg through targeted direct mail). Such considerations mean, in the words of Brennan and Brady, ${ }^{26}$ that the charity sector is an ideal domain for relationship marketing'.

On the other hand, investments in relationship marketing carry opportunity costs. It may be that the effort devoted to building close relationships with supporters would yield greater returns if people were simply asked to donate on an ad hoc basis. Moreover, successful relationship marketing could result in the formation of long-term relationships mostly with low financial status donors who give small amounts (perhaps less than the costs of acquiring and marketing to these individuals); rather than with higher status supporters likely to donate substantial sums in the longer period.
Donors to charities might not want relationships with the organisations they support.

Resistance to relationship marketing could result from charity donors becoming weary with being deluged with relationship marketing appeals, campaigns and communications, ${ }^{27}$ notably those transmitted by direct mail. Evans et al. $\mathrm{s}^{28}$ investigation of how members of the public interacted with direct marketing materials revealed that many consumers were highly sceptical of direct marketing and had grave concerns regarding both its lack of relevance and its potential to invade personal privacy. The latter was associated with (i) the perception that there was too much direct mail or telemarketing activity that intruded into a person's life, and (ii) a sense of resentment that outsiders were accumulating large amounts of detailed (market segmentation) information about an individual's circumstances and preferences. A minority of consumers actually 'felt intimidated' by direct marketing.

\section{CHARITY RELATIONSHIP MARKETING IN PRACTICE}

Payne $^{29}$ described relationship building through marketing in terms of the completion of a series of steps. First, people who have no direct relationship with the organisation are canvassed. Information about the organisation and what it can do is transmitted via advertising, events or public relations. These activities present the customer (donor) with promises, which are then fulfilled through interactive marketing. ${ }^{30}$ Certain message recipients will be persuaded to have direct encounters with the organisation. Contacts may be repeated, leading perhaps to a person becoming a supporter, and finally an advocate, of the organisation. (A 
'supporter', according to Payne, ${ }^{31}$ is someone who has positive commitment to the organisation; an advocate actively promotes it through positive word-of-mouth.) The literature on relationship marketing has specified the practical marketing tools that can be employed to facilitate progression through the various stages, as follows.

\section{Relationship advertising}

Advertising can be used to inform and educate potential donors about a charity and its services, to persuade people to give, and to remind donors about the charity's continuing need for income. Although advertising is often viewed as a 'mass' marketing medium, it does have the additional potential to create and nurture relationships. ${ }^{32}$ Advertisements (whether in the form of media advertisements, flyers, leaflets, posters, brochures or internet messages) may be crafted to offer representations of reality that, according to Stern, ${ }^{33}$ imitate relationships in much the same way as happens in a film, television programme or book'. Thus, Stern continued, the content and form of an advertisement have the capacity both to stimulate thoughts, feelings and actions relevant to a relationship and to define an implicit model of the relationship itself: "what it is and how it works'. ${ }^{34}$ This could influence a potential donor's assessments of the costs and benefits of entering, remaining with, or leaving a relationship with a charity. 'Relationship advertising', according to Bhattacharya and Bolton, ${ }^{35}$ can moreover 'facilitate intimacy and create a sense of identification with the organisation'. Thus it can impress the message recipient with the strength of a charity's altruistic concern (benevolence) for its beneficiaries; reinforce the belief that beneficiaries are extremely well-cared for; ${ }^{36}$ and convince the potential donor of the excellence of the charity's services.

Relationship advertising, according to Stern, ${ }^{37}$ should follow a progression from 'acquaintance' to 'buildup' to 'continuation'. Acquaintance involved attracting the customer's (donor's) attention so that he or she could form an initial image of the organisation. This first impression determined whether future interactions were likely. ${ }^{38}$ Acquaintance transferred to buildup when a message recipient was induced to try an interaction and test the outcome. If the organisation's responses were sympathetic and supportive, repeat interactions were likely. Eventually, buildup would merge into a 'continuation' situation characterised by 'familiarity and predictability'. ${ }^{39}$ Throughout the advertising process the organisation needed to evoke 'feelings of connectedness and liking' for the communicator. ${ }^{40}$

\section{Database marketing}

Modern database technology allows even a small charity to build, manage and evaluate relationships with specific donors efficiently and effectively. ${ }^{41}$ Information can be accumulated on donors' motives, preferences and characteristics, ${ }^{42}$ when and why donors are most likely to give ${ }^{43}$ and supporters' expectations of the charity's activities. ${ }^{44}$ Once established, a computer database of supporters can be used for targeted direct marketing and for detailed market segmentation (eg differentiating various groups of donors according to their socioeconomic and other characteristics). It then becomes possible to identify the sorts of messages that supporters are likely to regard as specifically relevant to their requirements. Hence, marketing communications may be customised for various donor groups and messages appropriate for each group 
can be presented. Typically, personalised messages are communicated via direct mail. It follows that a donor's perceptions of the immediate relevance to that particular individual of direct mail letters, pamphlets, brochures, etc, will represent an important indicator of his or her opinion of the quality of a charity's relationship marketing.

\section{Two-way marketing contacts}

Relationship advertising and direct marketing should provide the potential donor with sufficient information to enable the person to decide whether to support a charity. Thereafter, however, the organisation needs systems for communicating and interacting with donors in order to maintain and enhance a 'two-way' relationship. ${ }^{45}$ Hence donors might be encouraged to interact with the organisation through, for example, a website, toll free telephone numbers, freepost mail reply addresses, or e-mail. In response the charity can send out newsletters, information on upcoming events, etc, hence fostering the relationship. Charities that engage in two-way relationships with their donors are more likely to make the latter feel 'wanted'. ${ }^{46}$ Interactions should enable donors to provide feedback and express opinions, the analysis of which can assist in the segmentation of donors into meaningful categories.

Charities routinely employ public relations and special fundraising events to develop a donor's sense of affiliation with an organisation. For example, the Dog's Trust regularly invites its donors to attend open days at its kennels; organises mass dog walks in city parks and countryside areas; arranges fêtes, bazaars and jumble sales; operates a 'sponsor a dog' scheme, and so on. Numerous charities organise walks, 'fun runs' and other sporting activities. Entertainment events such as charity gala evenings, dinners and concerts where celebrities give their time free of charge, are common. Events of this nature are intended to stimulate within the donor a sense of shared values with the charity that in turn may help forge a relationship.

Two-way marketing communications can involve face-to-face contacts (as occur at charity sponsored events), or telephone calls, postal or electronic communications. Any form of interaction, however, has the capacity to help a donor learn more about a charity and its work, hence nurturing trust in the organisation and reducing uncertainties $^{47}$ (although a high degree of trust in an organisation can exist without concomitant feelings of commitment. Properly handled, moreover, interactions can encourage commitment to a charity by causing donors to believe that they are genuinely respected.

\section{AIMS OF RELATIONSHIP MARKETING}

Good quality relationship marketing should arouse a number of positive sentiments. First, the messages transmitted through various relationship marketing devices (direct marketing, relationship advertising, face-to-face contacts, etc) should be regarded by recipients (donors) as highly relevant to their personal interests. ${ }^{48-50}$ Relevant messages provide people with information that they perceive to be useful and helpful for satisfying their requirements. This can lead to a positive attitude towards the marketing communication bearing the message. ${ }^{51}$ Secondly, effective relationship marketing should engage message recipients interactively by making them (i) want to become involved with the charity, (ii) feel that the organisation is interested in their views, and (iii) believe that the charity genuinely respects its 
donors and wishes to have long-term relationships with them ${ }^{52-54}$ Duncan and Moriarty ${ }^{55}$ in particular emphasised the importance of relationship marketing communications as a device for managing interactions with message recipients. In the modern world, Duncan and Moriarty $^{56}$ argued, people desired and expected interactive relationships with organisations as a matter of routine. Hutt, Walker and Frankwick ${ }^{57}$ noted how these desires and expectations were becoming greater and ever far-reaching as a consequence of the introduction of new interactive technologies. Thus, according to Duncan and Moriarty, ${ }^{58}$ a critical desirable outcome of relationship marketing communications was that they stimulated enjoyable interactions between the organisation and the customer (donor in the present context).

A third fundamental (and somewhat obvious) objective of a fundraiser's relationship marketing is that it should be instrumental in establishing, developing and maintaining excellent relationships with donors..$^{59,60}$ Therefore, relationship marketing that significantly helps to nurture any or all of the basic elements of a good quality relationship is, ipso facto, high-quality relationship marketing. Roberts, Varki and Brodie ${ }^{61}$ argued that the conceptualisation and measurement of the quality of a relationship should proceed via the identification of the relationship's properties and/or attributes. They cited an extensive literature suggesting that the existence of an excellent relationship is evidenced by two major properties: trust and commitment (see Roberts, Varki and Brodie's ${ }^{62}$ Table 2 for details of relevant articles). 'Trust', the authors continued, had a general dimension that involved a partner's integrity, honesty and sincerity; and a 'benevolence' dimension associated with the belief that one partner was genuinely concerned for the other's welfare. Trust in an organisation's benevolence implies the belief that an organisation will always put the partner first, irrespective of circumstances. ${ }^{63}$ (In the present context the notion of 'benevolence' may reasonably be interpreted as a donor's perception that a charity is outstandingly beneficent vis-à-vis the people or causes to which it provides assistance.)

Many studies have concluded that general trust, commitment and trust in benevolence constitute distinct dimensions of the higher-order construct of relationship quality. ${ }^{64-66}$ Thus, according to Roberts, Varki and Brodie, ${ }^{67}$ they can reasonably be employed as measures of the relationship quality construct. Perceptions of general trust, commitment and trust in the partner's benevolence are, as Duncan and Moriarty $^{68}$ noted, in large part the consequence of relationship marketing communications, albeit in conjunction with impressions obtained from the outside world (from newspaper or television reports for example). Marketing is crucial to the process, however, because a core proposition of the relationship marketing literature is that a good relationship depends on the conviction that an organisation keeps its promises. ${ }^{69}$ Promises (eg that the charity will do good, really make a difference, deploy its resources wisely, etc.) are made through external marketing. The three critical elements of a good relationship - trust, commitment and trust in benevolence - are discussed further in the following sections.

\section{General trust}

Relationship marketing, according to Crosby ${ }^{70}$ is about cementing long-term collaborative relationships based on mutual trust'. Trust involves the belief 
that the partner will fulfil its obligations ${ }^{71}$ and fully satisfy a partner's needs. The existence of trust will increase a donor's confidence that a charity will use the donor's gift wisely. In the current context, trust can be interpreted as the donor's assumption that the charity can be relied upon to behave in such a manner that the long-term interests of its beneficiaries will be served in an excellent manner. Trust is evidenced by the perceptions that an organisation is credible, reliable, sincere and honest. ${ }^{72}$ In the service context, trust has been said to represent 'the single most powerful marketing tool' available to an organisation. $^{73}$

\section{Trust in a partner's benevolence}

A donor's perceptions that a charity is benevolent suggest that the person considers that the organisation is deeply concerned for the welfare of its beneficiaries and that its motives are entirely philanthropic and centred on the people or causes the charity was set up to help. Impressions of benevolence can be created, according to Waring et al. ${ }^{74}$ via marketing communications themed around 'caring', commitment to the beneficiary, compatibility between the organisation and the beneficiary, expressions of affection, warmth and protectiveness towards the charity's beneficiaries, and the organisation's determination to do good.

\section{Commitment}

Feelings of commitment arise as a person comes to like, value and understand an organisation. ${ }^{75}$ They involve the individual wanting to communicate and cooperate with the organisation, and to be close to it. Commitment to an organisation is the "highest stage of relational bonding, ${ }^{76}$ It implies the desire to remain within and to continue a relationship ${ }^{77}$ and has been posited to represent a crucial indicator of relationship quality. Indeed, Morgan and $\mathrm{Hunt}^{78}$ argued that commitment was the key construct that differentiated between successful and unsuccessful relationships. A strong sense of commitment to an organisation should moreover give rise to 'loyalty' which, according to Roman's ${ }^{79}$ review of the academic literature relating to this matter, is reflected not only by an individual's intentions to maintain an ongoing relationship with an organisation, but also to recommend it to others. Commitment to a relationship, therefore, may reasonably be assumed to indicate a person's satisfaction with its quality. ${ }^{80}$

It follows that 'excellent' relationship marketing (in the forms of relationship advertising, direct marketing, and two-way marketing contacts) in addition to transmitting messages that are regarded by donors as personally relevant and interactively engaging, will generate within donors' minds feelings of trust in a charity's integrity, trust in its benevolence and commitment to the organisation.

\section{A SUGGESTED MODEL}

Figure 1 presents a model implied by the above mentioned literature. Perceived relationship marketing quality is conceptualised as a formed attribute in the sense that its components 'add up to what the attribute means, ${ }^{81}$ It is defined as a latent variable determined as the sum total of the ratings of a number of specific activities (relationship advertising, direct marketing and two-way marketing contacts such as those occurring at open days, public relations events and through personal two-way communications) that make up an individual's overall perception of the quality of a charity's relationship 


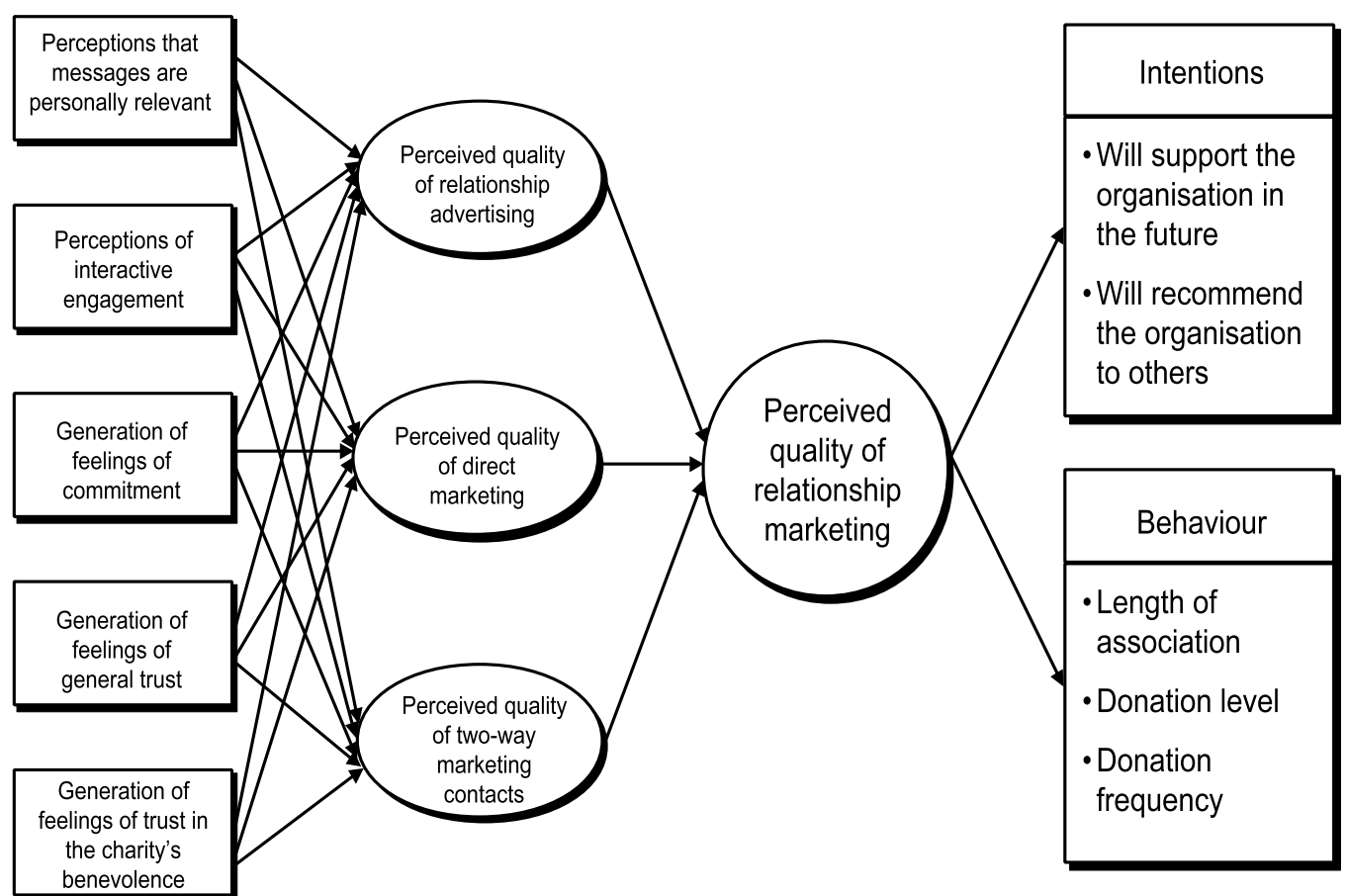

Figure 1 Hypothesised relationships

marketing. As a formed attribute, relationship marketing quality does not contain interchangeable components (as occurs with latent variables with reflective indicators). All the constituents must be present because they define the attribute, which itself will not be unidimensional: positive perceptions of a charity's relationship advertising need not be matched by equally favourable assessments of its other relationship marketing activities. Formative indicators need not be highly correlated, nor have high internal consistency.

Likewise, the quality of a charity's relationship advertising is regarded as a latent variable involving five formative indicators (message relevance, trust, etc). Thus, the quality of relationship advertising is assumed to be determined by its ability to generate feeling of trust, commitment, message relevance and interactive engagement. The same supposition is made in relation to a charity's direct marketing and its two-way contacts with donors. It is posited that the indicators are formative instead of reflective because they create (rather than exemplify) donors' perceptions of the quality of a charity's relationship advertising, direct marketing and two-way marketing contacts. Thus, for instance, relationship advertising may be said to be excellent if it causes people to regard messages as highly relevant to their interests, to trust the charity, etc. Yet, even thought trust, message relevance and so on, are clearly germane to the notion of excellent relationship advertising, they need not belong to a common underlying factor.

These three latent variables are then presumed to determine the perceived quality of relationship marketing as a second order construct, which in turn is hypothesised to correlate positively and significantly with three aspects of actual and two dimensions of intended behaviour. As all five of the behavioural dimensions were concrete, each was 
measured by a single item, hence avoiding wasteful redundancy and minimising the risk of picking up the substance of other attributes. ${ }^{82}$ The two behavioural intent items were adapted from Malhotra and Mukherjee, ${ }^{83}$ ie 'I am happy to continue giving to this charity for as long in the future as I can see', and 'I am happy to recommend other people to support this organisation'.

Actual behaviour was measured by asking people how long they had been supporting the particular charity (less than six months, 7-12 months, etc), the amount they had donated over the previous year (less than $\mathcal{E} 10, \mathcal{E}_{11-20}$, etc), and how frequently they had donated during the previous year.

\section{MEASURES OF RELATIONSHIP MARKETING QUALITY}

In line with the procedure recommended by Rossiter $^{84}$ the overall face validity of the main elements of the model presented in Figure 1 was checked via interviews with a sample of target raters, ie known donors to charitable organisations. Thus, 35 target raters were questioned in an open-ended manner about their perceptions of the meaning of a donor's 'relationship' with a charity. The group consisted of 35 individuals who, when approached (at random) at a street location at a central London railway and underground station, had confirmed that they regularly supported some charity or other and had donated to it on at least two occasions (apart from petty street collections) during the previous 12 months. Interviews began with the question 'As a supporter of this charity, what sorts of things make you feel good or bad about your relationship, as an individual, with the organisation?'. The words 'association' and 'connection' were added if necessary. Often a prompt was needed to induce the interviewee to make a response. This took the form of the question 'What sorts of things do you like or dislike about the ways in which the charity communicates and interacts with you?' A number of components were mentioned by at least a third of the respondents. The first major element comprised words associated with being 'appreciated', 'important', valued and/or respected, ie feelings that might reasonably be said to be connected with interactive engagement with the charity. Element two consisted of words relating to 'being close' to the organisation and feeling 'involved' with it, ie emotions related to a sense of being committed to the organisation. The third element comprised words about 'good communication', 'relevant information' and 'being told' about the charity's activities, ie words that emphasised the importance of 'message relevance'. Hence the respondents' interpretations of what a 'good relationship' with a charity involved (and by implication the perceptions that excellent relationship marketing should engender) broadly corresponded to the major elements of the suggested model.

Informed by these judgments, a review of the academic literature in the relationship marketing and relationship quality areas was then undertaken to identify (deductively) potentially relevant questionnaire items under these headings (interactive engagement, commitment and message relevance) plus the further dimensions of trust and benevolence that prior research in relationship marketing has insisted lie at the heart of excellent relationships. (See Schwab ${ }^{85}$ for theoretical justifications of this form of deductive approach). Consequently, 44 candidate items were listed under the five headings, the face validity of which was assessed independently by two marketing academics in the authors' home university. On the recommendation of the two assessors, 
Table 1: Questionnaire items
A. Personal relevance of messages (sources: references 15, 32, 47, 53 and 69)
Communications from the charity:
(i) focused heavily on things that I am personally interested in
(ii) really helped me personally to understand the charity and its work
(iii) were highly relevant to me as an individual
(iv) made me understand very clearly how my donations would help the charity's beneficiaries
(v) stimulated my personal interest in the charity.

B. Interactive engagement (sources: references 36, 45, 46, 53, 54 and 69)

Communications from the charity made me feel that:

(i) the charity really wanted me to interact with the organisation

(ii) the charity was genuinely interested in its supporters' views

(iii) the charity saw me as a respected partner in the relationship, not just as someone who gave money to the organisation

(iv) the charity was really committed to having a long-term relationship with me

(v) I was genuinely respected and that my support was really appreciated.

C. Commitment (sources: references 45, 54, 69 and 83)

Communications from the charity made me feel:

(i) emotionally committed to the organisation

(ii) heavily involved with the organisation

(iii) that the charity shared my personal values

(iv) a sense of 'belonging' to the charity

(v) that the charity's problems were my own.

D. Trust (sources: references 27, 69, 71 and 72)

Communications from the charity made me feel that the charity:

(i) could always be trusted to do its job properly

(ii) was honest and sincere in all its dealings with its donors

(iii) was completely credible

(iv) could always be relied upon to operate effectively

(v) would always use its assets wisely.

E. Benevolence (sources: references 54, 72 and 74)

Communications from the charity made me feel that the charity:

(i) put the welfare of its beneficiaries above everyone else, including its own managers, employees and administration

(ii) had aims that were totally benevolent

(iii) had employees who cared deeply for the charity's beneficiaries

(iv) would always 'go the extra mile' to help a beneficiary, no matter how difficult the task

(v) had great affection for its beneficiaries.

certain items that were nearly identical were combined and some others were reworded to improve their clarity. The remaining items are listed in Table 1.

\section{THE STUDY}

The sample for the investigation was obtained from four sources: interviews with attendees at three charity open day events, plus street interviews with commuters entering or leaving two railway stations in central London. Two of the open days were organised by a national charity concerned with an inherited medical condition, the other by an animal welfare organisation. Prima facie the people invited to these events could 
be expected to be regular supporters of the two charities and, as such, knowledgeable about the marketing messages and materials of these organisations. As a check, however, the individuals who (at random) were approached and invited to participate in the study at the open days were asked how many times they had donated to the relevant charity in the previous 12 months, and interviews were only conducted with supporters who had made three or more contributions. (The average number of donations over the past year was 4.6, taking into account standing orders.) As the open day interviews generated a limited number of responses (33, 36 and 31 interviews respectively), the authors and a group of eight undergraduate volunteer market research students approached members of the general public entering or leaving two railway stations in central London and queried whether they had donated to the same charity more than twice during the past year (apart from casually dropping coins into a charity collecting box) and, if so, whether they were 'regular supporters' of that charity.

Commuters who confirmed that this was the case were then asked to participate resulting (over a two-week period) in 41 further responses. The results from the four groups of donors were compared, no meaningful statistically significant differences emerging.

Participants in the study were presented with the questionnaire items listed in Table 1 (seven-point scales: $7=$ very much; $1=$ not at all) in a randomised order. The same questions were asked three times; first vis-à-vis the charity's advertisements, secondly in relation to its direct marketing materials and thirdly in respect of the organisation's two-way marketing contacts with donors through public relations and special fundraising events, open days and other interactive communications (a list of examples of which were given to the participant). Then the respondent was requested to complete the five behavioural questionnaire items. Responses to the five sets of items shown in Table 1 were sequentially factor analysed, first for the replies in respect of relationship advertising, then for direct marketing and then for two-way marketing contacts. Unidimensional solutions emerged in all cases. (The minimum value for the percentage of variance explained by the dominant factor in each of the 15 analyses was 68 per cent (maximum 77 per cent), and the minimum Cronbach's alpha value was 0.88 . Solutions were computed using SPSS 11 and their unidimensionality authenticated via the confirmatory factor analysis facility of the AMOS 4 package.) Accordingly, each item group was composited into a single scale reflecting the relevant construct thus creating 15 new variables (eg message relevance responses in relation to advertising, then in relation to direct marketing and then in relation to two-way marketing contacts; general trust vis-à-vis these three forms of relationship marketing, and so on).

\section{ESTIMATION}

The model shown in Figure 1 was estimated using the method of partial least squares (specifically PLS Graph Version $3,{ }^{86}$ as this is appropriate for a situation where constructs are defined by formative rather than reflective indicators and where the sample size is modest. (PLS Graph requires a sample size that is just ten times the magnitude of the number of indicators on the most extensive formative construct, ie $5 \times 10=50$ in the present case, or ten times the number of structural paths directed at a particular construct), 
Table 2: Weights and $R^{2}$ values for marketing methods*

\begin{tabular}{lllllll}
\hline & \multicolumn{2}{l}{ Relationship advertising } & \multicolumn{2}{c}{ Direct marketing } & \multicolumn{2}{l}{$\begin{array}{l}\text { Two-way marketing } \\
\text { contacts }\end{array}$} \\
\cline { 2 - 8 } & Weight & $\boldsymbol{R}^{\mathbf{2}}$ & Weight & $\boldsymbol{R}^{\mathbf{2}}$ & Weight & $\boldsymbol{R}^{\mathbf{2}}$ \\
\hline Message relevance & $0.28(3.95)$ & 0.41 & $0.41(4.44)$ & 0.60 & $0.33(2.51)$ & 0.55 \\
Interactive engagement & $0.23(2.99)$ & 0.39 & $0.38(4.03)$ & 0.50 & $0.39(3.06)$ & 0.60 \\
Commitment & $0.31(3.01)$ & 0.49 & $0.25(3.39)$ & 0.38 & $0.37(2.85)$ & 0.58 \\
General trust & $0.35(3.46)$ & 0.54 & $0.10(1.99)$ & 0.27 & $0.26(2.55)$ & 0.44 \\
Trust in benevolence & $0.42(3.68)$ & 0.61 & $0.22(3.02)$ & 0.34 & $0.41(4.67)$ & 0.62 \\
\hline
\end{tabular}

${ }^{\star}$ T-values in parentheses

whichever is the greater. Parameter values for the pathways and associated standard errors were calculated via the bootstrapping facility of the PLS Graph package. It is not necessary for the variables in a PLS estimation to be normally distributed prior to the application of the technique. A further advantage of the employment of PLS in the present context is that the use of formative indicators means that it is possible to compute the relative sizes of the impacts of each of the three forms of relationship marketing depicted in Figure 1 on overall perceptions of relationship marketing quality. Likewise for the relative impacts of message relevance, interactive engagement, etc, on perceptions of the quality of the three forms of relationship marketing.

\section{RESULTS}

\section{Item loadings on relationship marketing methods}

Table 2 displays the PLS regression weights and the squares of the loadings of the five formative indicators on each of the three components of relationship marketing quality (advertising, direct marketing, and 'other'). The squares of the loadings ( $R^{2}$ values) are listed because they show the percentages of the variation of the latent variable shared with each indicator. Fornell and $\mathrm{Cha}^{87}$ argued that these $R^{2}$ values should exceed 0.5 , meaning that at least half of the variance in the latent variable is shared with the indicator (This implies that loadings need to be greater than 0.71 in order to be regarded as 'significantly' associated with the relevant latent variable (as $\left.[0.707]^{2}=0.5\right)$. A more common and less severe criterion for accepting the 'significance' of loadings is that they should account for at least a quarter of shared variation (ie $\left.R^{2}>0.25\right) .{ }^{88}$ It can be seen from Table 1 that all but one of the squared loadings on the 'two-way marketing contacts' index were greater than 0.5 , and the fifth (at $R^{2}=0.44$ ) was high relative to the $R^{2}>0.25$ criterion. The greatest impact on the two-way marketing contacts index was exerted by the ability of these contacts to stimulate feelings of trust in a charity's benevolence towards the people it helped, closely followed by their capacities to stimulate interactive engagement and induce a sense of commitment. The attributes of message relevance and interactive engagement were most heavily associated with the direct marketing index (as might be expected a priori in relation to personalised direct marketing communications). This index was associated less strongly with feelings of commitment, trust or benevolence, implying that the charities' direct marketing activities were less likely to evoke desirable emotions in these regards. The highest loadings on the 
Table 3: Perceived quality of relationship marketing

\begin{tabular}{llll}
\hline & Weight & T-value & $\boldsymbol{R}^{\mathbf{2}}$ \\
\hline Incoming & & & \\
& & & \\
- Relationship advertising & 0.40 & 6.33 & 0.61 \\
- Direct marketing & 0.26 & 3.48 & 0.43 \\
- Two-way marketing contacts & 0.35 & 4.39 & 0.55 \\
- Average $R^{2}$ & & & 0.53 \\
Outgoing & & & \\
- Will support the charity in the future & 0.42 & 3.99 & 0.42 \\
- Will recommend the charity & 0.40 & 3.11 & 0.40 \\
- Length of association & 0.50 & 3.98 & 0.50 \\
- Donation level & 0.50 & 3.48 & 0.50 \\
- Donation frequency & 0.26 & 2.01 & 0.26 \\
\hline
\end{tabular}

Table 4: Squared correlations among latent constructs

\begin{tabular}{llll}
\hline A. Relationship advertising & 1 & & \\
B. Direct marketing & 0.33 & 1 & 1 \\
C. Two-way relationship contacts & 0.35 & 0.32 & C \\
\hline
\end{tabular}

relationship advertising index were its abilities to create trust in and commitment to a charity. Advertising, however, appeared less likely to stimulate the belief that the charity wanted its supporters to interact with the organisation.

\section{Perceived quality of relationship marketing}

Table 3 shows the relative impacts of donors' perceptions of the calibres of a charity's advertising, direct marketing and other relationship marketing activities on their overall evaluations of the quality of the organisation's relationship marketing. It can be seen from Table 3 that the (perceived) excellence of a charity's advertising (in the sense that the advertising was relevant to relationship building) had the strongest connection with the overall relationship marketing variable, followed by 'two-way marketing contacts' (events, etc), with direct marketing in third place.
Connections between, on the one hand, the perception that a charity's relationship marketing was excellent and, on the other, the behavioural variables listed in Table 3 were all positive and statistically significant. The most powerful impacts of a donor holding high opinions of the quality of an organisation's relationship marketing were on relationship duration and level of donation. 'Word-of-mouth' was significantly more favourable among people with high opinions of relationship marketing quality, frequencies of donation were significantly greater and donors were more likely to continue giving in the future.

The discriminant validity of a partial least squares model is assessed by determining whether each latent variable shares more variance with its indicators than it shares with other latent variables in the model. In general, the average of the $R^{2}$ values between a latent variable and its indicators should be greater than the $R^{2}$ values between that latent variable 
and other latent variables. Table 4 gives the squared correlations between the three central latent variables used in the model. A comparison of the $R^{2}$ values listed in Table 4 with those of Table 2 and the average $R^{2}$ value of 0.53 shown in Table 1 for the three formative indicators of the perceived quality of relationship marketing reveals that this benchmark is satisfied in all cases.

\section{CONCLUSION}

Donors' perceptions of the quality of a charity's relationship marketing were strongly associated with their perceptions of the relationship-building characteristics of the organisation's advertising in terms of the ability of the advertising to present a supporter with personally relevant messages, to convince the person of the charity's desire to interact with the individual, and to generate feelings of trust in and commitment to the charity. A charity's two-way personal contacts with donors such as those experienced at public relations and special fundraising events also exerted a heavy influence on perceived marketing relationship quality. Direct marketing had the lowest impact, although the influence was still significant. Moreover, while charities' direct marketing activities were significantly associated with donors' perceptions that the messages received were highly relevant and interactively engaging, feelings of commitment, general trust and trust in a charity's benevolence only explained smaller amounts of the total variation in this particular latent variable.

A possible reason for the comparatively low impact of direct marketing on supporters' opinions concerning overall relationship marketing quality could perhaps be associated with the problem noted in the commercial world $^{89}$ of individuals being deluged with direct marketing materials, the marginal impact of which may be minimal. Possibly, much of the content of direct marketing communications is ignored, whereas emotive messages transmitted in advertisements and/or one-to-one interactions (such as those experienced at charity events) are noticed and appreciated. This implies that British charities might need to devote relatively more of their marketing resources to public relations events and other one-to-one interactions at the expense of direct marketing. Expenditures on advertising, conversely, appear to yield a sound return where relationship formation is concerned, provided the advertising is crafted in order to create relationships.

To the extent that relationship marketing activities engender in donors the beliefs and feelings outlined in Table 1 , such activities are likely to generate valuable payoffs in terms of supporter retention and longevity, willingness to engage in positive word-of-mouth, and the frequency and levels of supporters' donations. It would appear therefore that investments in relationship marketing by charitable organisations are worthwhile. Clearly, the topic of relationship marketing quality is worthy of further and extensive research. The present study examined just five elements of marketing quality that have been suggested by prior literature in the 'relationship quality' field, as informed by the opinions of a small sample of 35 charity donors. An immediate issue that springs to mind is the determination of the antecedents of perceptions of the calibres of each of the five elements (message relevance, interactive engagement, etc). Also, it would be useful to investigate whether additional elements should be included in the model so as to explain more fully a donor's assessment of the quality of an organisation's relationship advertising, 
direct marketing and other contacts. A somewhat different, but nevertheless intriguing, line of further research would be the exploration of the characteristics (sociodemographic and psychometric) of donor groups that are especially receptive to relationship marketing. If supporters with high lifetime donor values possess attitudes towards relationship marketing that differ from donors who give relatively little then it is essential to explore in detail the reasons for the disparity.

\section{References}

1 Burnett, K. (1992) 'Relationship fundraising', White Lion Press, London.

2 Tapp, A. (1995) 'Relationship fundraising techniques in charities: Are they used and do they work?' Journal of Database Marketing, Vol. 2, No. 4, pp. 328-343.

3 Bennett, R. and Gabriel, H. (1998) 'Adoption and management of database marketing within the UK charity sector', Journal of Targeting, Measurement and Analysis for Marketing, Vol. 6, No. 4, pp. 311-327.

4 Brennan, L. and Brady, E. (1999) 'Relating to marketing: Why relationship marketing works for not-for-profit organisations', International Journal of Nonprofit and Voluntary Sector Marketing, Vol. 4, No. 4, pp. 327-337.

5 McGrath, S. (1997) 'Giving donors good reason to give again', Journal of Nonprofit and Voluntary Sector Marketing, Vol. 2, No. 2, pp. 125-135.

6 Sargeant, A. (2001) 'Using donor lifetime value to inform fundraising strategy', Nonprofit Management and Leadership, Vol. 12, No. 1, pp. 25-38.

7 Toohill, J., Mullins, L., Barclay, J. and Sadnicki, M. (1997) 'Turning data into donations: A predictive model for individual giving', Journal of Nonprofit and Voluntary Sector Marketing, Vol. 2, No. 2, pp. 136-147.

8 Advertising Association (2003) 'The marketing pocket book', NTC Publications Ltd, Henley-on-Thames.

9 The Metro (2003) 'Charities get just 10p in the $f^{1}$ ', 21st October, p. 13.

10 Marketing Business (2003) 'Hard-edged success', editorial report, Marketing Business, November/December, p. 10.

11 Magson, N. (1999) 'Donors: How much do they give in a lifetime?' International Journal of Nonprofit and Voluntary Sector Marketing, Vol. 4, No. 1, pp. 11-25.

12 Stoddard, C. (1996) 'Targeting donors by post and by phone', Charity, Vol. 13, No. 10, pp. 28-29.

13 Bennett and Gabriel (1998) op. cit.

14 Magson (1999) op. cit.
15 Bhattacharya, C. and Bolton, R. (2000)

'Relationship marketing in mass markets', in Sheth, J. and Parvatiyar, A. (eds) 'Handbook of relationship marketing', Sage Publications Ltd., London, pp. 327-354.

16 Key Note (1997) 'Direct marketing', Key Note Reports Ltd., London.

17 Bennett and Gabriel (1998) op. cit.

18 Carter, M. (1995) 'Charities opt for brand aid', Fundraising, Vol. 17, September, p. 20.

19 Saxton, J. (1995) 'A strong charity brand comes from strong beliefs and values', Journal of Brand Management, Vol. 2, No. 4, pp. 211-220.

20 Bennett, R. (2004) 'Predicting the lifetime durations of donors to charities', Journal of Nonprofit and Public Sector Marketing, in press.

21 Burnett (1992) op. cit.

22 Berry, L. (1995) 'Relationship marketing of services - growing interest, emerging perspectives', Journal of the Academy of Marketing Science, Vol. 23, No. 4, pp. 236-245.

23 Guenzi, P. (2003) 'Antecedents and consequences of a firm's selling orientation', European Journal of Marketing, Vol. 37, Nos. 5/6, pp. 706-727.

24 Conway, T. (1997) 'Strategy versus tactics in the not-for-profit sector: A role for relationship marketing?', Journal of Nonprofit and Voluntary Sector Marketing, Vol. 2, No. 1, pp. 42-51.

25 Bennett, R and Gabriel, H. (1999) 'Charity involvement and customer preference for charity brands', Journal of Brand Management, Vol. 7, No. 1, pp. $49-66$.

26 Brennan and Brady (1999) op. cit., p. 331.

27 Crosby, L. (2002) 'Exploding some myths about customer relationship management', Managing Service Quality, Vol. 12, No. 5, pp. 271-277.

28 Evans, M., Patterson, M. and O'Malley, L. (2001) 'The direct marketing-direct consumer gap: Qualitative insights', Qualitative Market Research: An International Journal, Vol. 4, No. 1, pp. 17-24.

29 Payne, A. (2000) 'Relationship marketing: The UK perspective', in Sheth, J. and Parvatiyar, A. (eds) 'Handbook of relationship marketing', Sage Publications Ltd., London, pp. 39-68.

30 Bitner, M-J. (1995) 'Building service relationships: It's all about promises', Journal of the Academy of Marketing Science, Vol. 23, No. 4, pp. 246-251.

31 Payne (2000) op. cit.

32 Stern, B. (1997) 'Advertising intimacy: Relationship marketing and the services consumer', Journal of Marketing, Vol. 26, No. 4, pp. 7-20.

33 Ibid., p. 7.

34 Ibid., p. 8.

35 Bhattacharya and Bolton (2000) op. cit., p. 333

36 Hochschild, A. (1983) 'The managed heart', University of California Press, Berkeley, CA.

37 Stern (1997) op. cit.

38 Perlman, D. and Fehr, B. (1987) 'The development of intimate relationships', in Perlman, D. and Duck, S. (eds) 'Intimate relationships: Development, dynamics and deterioration', Sage, Newbury Park, pp. $13-42$. 
39 Perlman and Fehr (1987) op. cit.

40 Stern (1997) op. cit.

41 Bennett and Gabriel (1998) op. cit.

42 Perrien, J. and Ricard, L. (1995) ' The meaning of a marketing relationship: A pilot study', Industrial

Marketing Management, Vol. 24, No. 3, pp. 317-327.

43 Brennan and Brady (1999) op. cit.

44 Conway (1997) op. cit.

45 Grönroos, C. (2000) 'Relationship marketing: The

Nordic School perspective', in Sheth, J. and

Parvatiyar, A. (eds) 'Handbook of relationship marketing,', Sage Publications Ltd., London, pp. 95-117.

46 Duncan, T. and Moriarty, S. (1998) 'A

communication-based marketing model for managing relationships', Journal of Marketing, Vol. 62, No. 2, pp. 1-13.

47 Hakansson, H. and Snehota, I. (2000) 'The IMP perspective', in Sheth, J. and Parvatiyar, A. (eds) 'Handbook of relationship marketing', Sage Publications Ltd., London, pp. 69-93.

48 Bruce, I. (1994) 'Meeting need: Successful charity marketing', ICSA Publishing, Hemel Hempstead.

49 Perrien and Ricard (1995) op. cit.

50 Coviello, N., Brodie, R. and Munro, H. (1997)

'Understanding contemporary marketing: A classification scheme', Journal of Marketing Management, Vol. 13, No. 6, pp. 501-522.

51 Bhattacharya and Bolton (2000) op. cit.

52 Hochschild (1983) op. cit.

53 Celsi, R. and Olson, J. (1988) 'The role of involvement in attention and comprehension processes', Journal of Consumer Research, Vol. 15, No. 4, pp. 210-224.

54 Roberts, K., Varki, S. and Brodie, R. (2003) 'Measuring the quality of relationships in consumer services: An empirical study', European Journal of Marketing, Vol. 37, No. 1, pp. 169-196.

55 Duncan and Moriarty (1998) op. cit.

56 Ibid.

57 Hutt, M., Walker, B. and Frankwick, G. (1995) 'Hurdle the cross-functional barriers to strategic change', Sloan Management Review, Vol. 36, No. 1, pp. 22-30.

58 Duncan and Moriarty (1998) op. cit.

59 Henning-Thurau, T. and Klee, A. (1997) 'The impact of customer satisfaction and relationship quality on customer retention: A critical reassessment and model development', Psychology and Marketing, Vol. 14, No. 8, pp. 737-764.

60 Roberts et al. (2003) op. cit.

$61 \mathrm{Ibid}$.

62 Ibid.

63 Anderson, E. and Weitz, B. (1989) 'Determinants of continuity in conventional industrial dyads', Marketing Science, Vol. 8, No. 3, pp. 310-323.

64 Dwyer, F., Schurr, P. and Oh, S. (1987) 'Developing buyer-seller relationships', Journal of Marketing, Vol. 51, No. 2, pp. 11-27.

65 Crosby, L., Evans, K. and Cowles, D. (1990) 'Relationship quality in services selling: An interpersonal influence perspective', Journal of
Marketing, Vol. 54, No. 1, pp. 68-81.

66 Kumar, N., Scheer, L. and Steenkamp, J. (1995)

'The effects of supplier fairness on vulnerable resellers', Journal of Marketing Research, Vol. 32, No. 1, pp. 54-65.

67 Roberts et al. (2003) op. cit.

68 Duncan and Moriarty (1998) op. cit.

69 Rosen, D. and Surprenant, C. (1998) 'Evaluating relationships: Are satisfaction and quality enough?' International Journal of Service Industry Management, Vol. 9, No. 2, pp. 103-125.

70 Crosby (2002) op. cit., p. 272.

71 Swan, J., Bowers, M. and Richardson, L. (1999) 'Customer trust in the salesperson: An integrative review and meta-analysis of the empirical literature', Journal of Business Research, Vol. 44, No. 2, pp. 93-107.

72 Morgan, R. and Hunt, S. (1994) 'The commitment-trust theory of relationship marketing', Journal of Marketing, Vol. 58, No. 3, pp. 20-38.

73 Berry (1995) op. cit.

74 Waring, E., Tillman, M., Frelick, L., Russell, L. and Weisz, G. (1980) 'Concepts of intimacy in the general population', Journal of Nervous and Mental Disease, Vol. 168, No. 3, pp. 471-474.

75 Keating, B., Rugimbana, R. and Quazi, A. (2003) 'Differentiating between service quality and relationship quality in cyberspace', Managing Service Quality, Vol. 13, No. 3, pp. 217-232.

76 Dwyer et al. (1987) op. cit.

77 Shemwell, D., Yavas, U. and Bilgin, Z. (1998) 'Customer-service provider relationships: An empirical test of a model of service quality, satisfaction and relationship-orientated outcomes', International Journal of Service Industry Management, Vol. 9, No. 2, pp. 155-168.

78 Morgan and Hunt (1994) op. cit.

79 Roman, S. (2003) 'The impact of ethical sales behaviour on customer satisfaction, trust and loyalty to the company: An empirical study in the financial services industry', Journal of Marketing Management, Vol. 19, Nos. 9/10, pp. 915-939.

80 Moorman, C., Zaltman, G. and Despande, R. (1992) 'Relationships between providers and users of market research: The dynamics of trust within and between organisations', Journal of Marketing Research, Vol. 26, No. 3, pp. 314-329.

81 Rossiter, J. (2002) 'The C-OAR-SE procedure for scale development in marketing', International Journal of Research in Marketing, Vol. 19, No. 4, pp. 305-335.

82 Drolet, A. and Morrison, D. (2001) 'Do we really need multi-item measures in service research?', Journal of Service Research, Vol. 3, No. 3, pp. 196-204.

83 Malhotra, N. and Mukherjee, A. (2003) 'Analysing the commitment-service quality relationship: A comparative study of retail banking call centres and branches', Journal of Marketing Management, Vol. 19, Nos. 9/10, pp. 941-972.

84 Rossiter (2002) op. cit.

85 Schwab, D. (1980) 'Construct validity in 
organisational behaviour', in Straw, B. and Cumings, L. (eds) 'Research in organisational behaviour', JAI Press, Greenwich CT, pp. 3-43.

86 Chin, W. (2001) 'PLS-Graph user's guide', version 3, Soft Modelling Inc., Houston.

87 Fornell, C. and Cha, J. (1994) 'Partial least squares', in Bagozzi, R. (ed.) 'Advanced methods of marketing research', Basil Blackwell, Cambridge MA, pp. 52-78.

88 Nunnally, J. and Bernstein, I. (1994) 'Psychometric theory', 3rd edn, McGraw-Hill, New York.

89 Evans et al. (2001) op. cit. 